\title{
Seluk Beluk Metode Analisis Social Returns on Investment
}

Nama: M.Alvin.A.S

Email: alvinas2751@gmail.com

The Social Return on Investment (SROI) adalah sebuah bentuk evaluasi yang menawarkan jawaban atas pertanyaan-pertanyaan desain evaluasi, niat dan pemanfaatan. SROI berusaha untuk menggunakan informasi yang sangat diawasi tentang pemasukan sumber daya, kegiatan yang diberlakukan, proses yang terinspirasi dan hasil yang bisa dicapai secara formatif untuk mengevaluasi usaha sosial. SROI juga dirancang untuk memberikan penetrasi terhadap pendanaan oleh swasta maupun entitas public demi inovasi yang dalam, dan penyediaan yang lebih luas dari program untuk memulihkan atau mencegah terjadinya penderitaan dan memenuhi potensi manusia (Yates \& Marra, 2017).

Pernah terjadi pada tahun 2005 dimana kampanye Green and Clean dimulai dengan dimulai dengan serangkaian kompetisi lingkungan yang didukung oleh media. Analisa dilakukan untuk mengetahui seberapa besar dampak kampanye ini, studi ini bersifat retrospektif dan berdasarkan hasil aktual dari perspektif masyarakat lokal. Singkat cerita kompetisi kampanye tersebut berhasil mendorong komunitas untuk mendapatkan berbagai innovasi-innovasi sosial. Studi ini berkontribusi pada teori pertukaran sosial, yang menyatakan bahwa partisipasi muncul dari analisis biaya-manfaat individu. Teori pertukaran sosial percaya bahwa melibatkan berbagai pemangku kepentingan untuk menilai hasil memungkinkan studi untuk melegitimasi analisis.

Analisis SROI banyak digunakan untuk mencari outcome atau hasil dari suatu permasalahan, lima contoh kasus SROI berikut bisa menggambarkan bagaimana SROI sudah membantu banyak dalam menyelesaikan permasalahan sosial. Untuk yang pertama berjudul "The health and social impact of Blood Donors Associations: A Social Return on Investment" (SROI) analisis dimana SROI disini digunakan untuk menganalisis Dampak Kesehatan terhadap donor darah (Ricciuti \& Bufali, 2019). Di urutan kedua ada "The social value of the arts for care home residents in England: A Social Return on Investment (SROI) analysis of the imagine Arts programme yang dimana analisis SROI ini dibuat bertujuan untuk melibatkan orang yang lanjut usia untuk beraktivitas kreatif dan dapat memberikan manfaat keterlibatan positif untuk orang lanjut usia. (Bosco, Schneider, \& Broome, 2019). SROI analisis yang ketiga berjudul Return on Investment analysis and its applicability to community disaster preparedness activities: Calculating costs and returns dimana bertujuan untuk menghitungan biaya dan pengembalian selama kegiatan kesiapsiagaan bencana masyarakat (Kousky, Ritchie, Tierney, \& Lingle Brett, 2019). Untuk urutan keempat ada Using Social Return on Investment to evaluate the public art exhibit Breathing Lights dimana SROI analisis digunakan untuk mengevaluasi Pamernan seni public bertemakan Lampu Pernafasan (Refki, Mishkin, Avci, \& Abdelkarim, 2020). Dan untuk yang terakhir ada artikel berjudul Social Return On Investment Of An Ideal Approach To Multiple Sclerosis Within The Spanish National Health System dimana analisis SROI disini digunakan untuk melakukan pendekatan ideal untuk mengelola MS (Multiple sclerosis) dan SNHS (Spanish National Health system) (E. Moral, et al., 2018).

Setiap metode analisis harus mempunyai nilai lebih agar bisa menjadi alasan sebuah instansi atau pihak yang akan menggunakan analisis metode SROI ini, SROI mempunyai kelebihan seperti : SROI memiliki banyak informasi yang tersedia tentang kerangka konseptual studinya, ada juga variabilitas yang besar dalam bagaimana SROI diterapkan di seluruh 
intervensi di komunitas yang berbeda. SROI memberikan ukuran kelayakan dengan pendekatan berbasis pasar yang dapat mendorong masyarakat untuk meningkatkan berbagai inovasi sosial, seperti pengolahan sampah berbasis masyarakat, model bank sampah dan berbagai pemasaran sosial yang melibatkan masyarakat sosial. Begitu juga dalam dunia yang kita tinggali ini, tidak ada sesuatu yang sempurna begitu juga dengan metode ini, metode ini mempunyai beberapa kelemahan sebagai berikut: Studi ini berfokus pada perspektif komunitas selama waktu pengamatan. Masyarakat mungkin mengalami berbagai tingkat kemampuan dan sumberdaya yang berkontribusi pada pencapaian program. Ada kekurangan literatur yang dapat memberikan proksi keuangan dan tidak ada metode yang diterima umum untuk mengukur nilai-nilai manfaat sosial. Studi ini menyangkut kegiatan satu tahun, ini adalah pengamatan singkat.

\section{Review artikel}

\section{Reference}

Pratono, A.H., Suyanto, D Marciano, Zurbrügg, C. (2017) The Hong Kong Journal of Social Work 51 (01n02), 93-114

Kousky, C., Ritchie, L., Tierney, K., \& Lingle, B. (2019, Desember). Return on investment analysis and its applicability to community disaster preparedness activities: Calculating costs and returns. International Journal of Disaster Risk Reduction, 41(University of Pennsylvania, Univeristy of Colorado Boulder and Professor Emerita of Sociology,Oklahoma State University and an Associate Professor in OSU's Department of Sociology.), 101-296.

Bosco, A., Schneider, J., \& Broome, E. (2019, Juni 01). The social value of the arts for care home residents in England: A Social Return on Investment (SROI) analysis of the Imagine Arts programme. Maturitas, 124(University of Nottingham), P15-24.

Ricciuti , E., \& Bufali, M. V. (2019, April). The health and social impact of Blood Donors Associations: A Social Return T on Investment (SROI) analysis. Evaluation and Program Planning, 73(Bocconi University, Strathclyde Business School), 204-213.

Yates, B., \& Marra, M. (2017, Oktober). Introduction: Social Return On Investment (SROI. Evaluation and Program Planning, 64(American University, University of Salerno.), 95-97.

Refki, D., Mishkin, K., Avci, B., \& Abdelkarim, S. (2020, April). Using social return on investment to evaluate the public art exhibit Breathing Lights. Poetics, 79(University at Albany, State University of New York.), 101-401.

E Moral, O Fernandez, P Carrascal, M Merino, Jimenez-Torres, M., Gomez-Garcia, T., . . R Manzanares. (2018, Oktober). Social Return On Investment Of An Ideal Approach To Multiple Sclerosis Within The Spanish National Health System . Value in Health, 21(PND-50), S337. 